\title{
Disease Progress Based on Effects of Verticillium dahliae and Pratylenchus penetrans on Gas Exchange in Russet Burbank Potato
}

\author{
Ibrahim A. M. Saeed, Ann E. MacGuidwin, and Douglas I. Rouse
}

Department of Plant Pathology, University of Wisconsin, 1630 Linden Drive, Madison 53706.

Accepted for publication 14 January 1997.

\section{ABSTRACT}

Saeed, I. A. M., MacGuidwin, A. E., and Rouse, D. I. 1997. Disease progress based on effects of Verticillium dahliae and Pratylenchus penetrans on gas exchange in Russet Burbank potato. Phytopathology 87:440445.

The interactive effects of concomitant infection by the nematode Pratylenchus penetrans and the fungus Verticillium dahliae on symptom expression in Russet Burbank potato was studied in growth chamber experiments. Treatments were $P$. penetrans at three initial densities, $V$. dahliae at one inoculum density, the combination of the nematode at these three densities and the fungus, and a noninfested control. Gas exchange was measured nondestructively in leaf cohorts of different ages, one to three times weekly, with a LI-COR portable photosynthesis system. The singlepathogen treatments had no effect on assimilation or transpiration rates, but joint infection had a significant impact. In concomitant infection, photosynthesis was impaired more than transpiration, so estimates of leaf health were based on carbon assimilation rates only. Reductions in assimilation rate were apparent before the onset of visual symptoms. Assimilation rates decreased as much as $44 \%$ in the top, and newest, leaves of concomitantly infected plants, compared to rates in control plants. Even so, the health of newly produced leaves did not become progressively worse through time. With light use efficiency less than $0.20 \mathrm{~mol}$ of $\mathrm{CO}_{2}$ fixed per mol of photosynthetically active radiation used as the criterion for disease incidence, disease progressed acropetally from the oldest to the youngest leaves. In plants infected with $P$. penetrans $(0.8$ nematodes per $\mathrm{cm}^{3}$ of soil) in combination with $V$. dahliae, all leaves in cohorts 1 and 2 were symptomatic by 45 days after planting, and leaves in cohorts 3 to 6 became symptomatic at weekly intervals thereafter. For the control and single-pathogen treatments, the first time that light use efficiency fell below 0.20 in all leaves in cohort 1 was 71 days after planting. Concomitant infection reduced leaf life span by about 3 weeks. Both visual and physiological symptom expression were invariant to differences in initial nematode inoculum densities ranging from 0.8 to 2.5 nematodes per $\mathrm{cm}^{3}$ of soil in one experiment and from 1.3 to 4.1 nematodes per $\mathrm{cm}^{3}$ of soil in a second experiment.

Additional keywords: potato early dying disease, root-lesion nematode, vascular wilt.
Beckman (1) proposed a conceptual model of disease progress for Verticillium and other vascular wilt fungi that recognizes a series of sequential but overlapping events including infection, colonization, and growth by the pathogen in the host and symptom expression by the plant. Infection events for Verticillium dahliae associated with potato occur early, even as potato plants are emerging, and continue as the root system expands $(10,16)$. Colonization of the xylem progresses over a period of several weeks to several months $(7,19,21)$. It is not fully understood how other biological agents such as root-lesion nematodes affect these processes.

Visual symptoms in potato infected by $V$. dahliae include wilting, chlorosis, and an acropetal progression of premature leaf senescence. The symptoms first appear on older leaves positioned low in the canopy. Prior to the occurrence of visual symptoms, physiological processes are affected. Bowden and Rouse (3), examining the whole-plant physiological processes of photosynthesis and transpiration, identified three phases in disease progression in infection of potato by $V$. dahliae. In the latent phase, plants are infected but exhibit no symptoms. The latent period is shorter when based on physiological rather than visual symptoms. In the local phase, physiological symptoms are apparent on some but not all leaves, and even adjacent leaflets may present different types and degrees of symptoms. In the systemic phase, even new leaves show some degree of physiological impairment as well as visual symptoms.

Corresponding author: A. E. MacGuidwin

E-mail address: macguid@plantpath.wisc.edu

Publication no. P-1997-0228-02R

(C) 1997 The American Phytopathological Society
A synergistic interaction of $V$. dahliae and $P$. penetrans affecting visual symptom expression in the field and yield loss has been established $(9,14,15,17,22,23)$. The progress of visual symptoms and defoliation from 70 to 126 days after planting was greater in Russet Burbank potato grown in microplots infested with $P$. penetrans and $V$. dahliae than in plants infected with $V$. dahliae alone or in control plants (15). The date of onset and progress of senescence in Superior potato grown in microplots infested with $V$. dahliae were enhanced by adding $P$. penetrans (9). Comparable studies have demonstrated that infection by $P$. penetrans can reduce tuber yield (20).

The objective of our study was to determine in what respects $P$. penetrans affects the temporal and spatial presentation of physiological symptoms associated with $V$. dahliae infection of Russet Burbank potato. We used the experimental conditions, cultures, and facilities used by Bowden and Rouse $(2,3)$ and Bowden et al. (4) to demonstrate the effect of $V$. dahliae on gas exchange in potato. Using inoculum doses of 100 or more propagules of $\mathrm{V}$. dahliae per gram of soil, they determined that the fungus impaired $\mathrm{CO}_{2}$ assimilation, stomatal conductance, and transpiration before the onset of visual symptoms. In a companion paper, we describe the general nature of the nematode-fungus interaction as it affects gas exchange (24).

\section{MATERIALS AND METHODS}

Gas exchange studies were conducted in a growth chamber at the University of Wisconsin Biotron, a controlled plant growth facility. Details about plant tissue culture propagation, inoculum production and procedures, and plant maintenance are presented elsewhere (24). Treatments were $P$. penetrans at three inoculum densities, $V$. 
dahliae at one inoculum density, $P$. penetrans at these three inoculum densities in combination with $V$. dahliae, and a noninoculated control. Treatments were assigned to pots arranged in a randomized block design with four replications. The experiment was repeated three times. Data from two representative experiments are reported here, with $P$. penetrans at inoculum doses of $0.8,1.8$, and 2.5 nematodes per $\mathrm{cm}^{3}$ of soil in one experiment and $1.3,2.7$, and 4.1 nematodes per $\mathrm{cm}^{3}$ of soil in the other experiment. An inoculum of $0.5 \mathrm{~g}$ of ground dried rye seed containing $V$. dahliae was added per liter of soil mix. On the basis of an assay of the inoculum, the initial dose was 40 propagules per $g$ of soil. On the basis of a soil assay after the addition of the inoculum, there were 5.4 propagules per $g$ of soil. Population densities of both the nematode and the fungus are representative of levels assayed in commercial potato fields in Wisconsin. Nematode and fungus inocula were applied when potato plants propagated in tissue culture and hardened in soil were transplanted to 20 -liter pots containing equal parts, by volume, of Plainfield loamy sand soil and vermiculite.

Data collection began 20 days after transplanting (hereafter referred to as planting). Carbon assimilation rates, transpiration, and other related parameters were measured with a LI-6200 portable photosynthesis system (Li-Cor, Lincoln, NE) or calculated from gas exchange measurements. The most recent fully expanded leaflet present when data collection began was designated cohort 1 .
TABLE 1. Summary of overall repeated measure analysis of net photosynthesis and transpiration data for leaf cohort 1 of Russet Burbank potato plants inoculated with Verticillium dahliae (Vert), Pratylenchus penetrans (Nema), or both pathogens

\begin{tabular}{|c|c|c|c|c|c|c|}
\hline \multirow[b]{2}{*}{ Source of variation } & \multicolumn{3}{|c|}{ Experiment 1} & \multicolumn{3}{|c|}{ Experiment 2} \\
\hline & $\mathrm{df}^{\mathrm{a}}$ & $\mathrm{MS}^{\mathrm{b}}$ & $P$ value $^{\mathrm{c}}$ & $d f^{a}$ & $\mathrm{MS}^{\mathrm{b}}$ & $P$ value $^{\mathrm{c}}$ \\
\hline \multicolumn{7}{|l|}{ Assimilation rate } \\
\hline Time & 13 & 970.9 & 0.00 & 8 & 911.3 & 0.00 \\
\hline Time * Block & 39 & 6.6 & 0.01 & 24 & 3.2 & 0.07 \\
\hline Time $*$ Vert & 13 & 53.3 & 0.00 & 8 & 7.1 & 0.00 \\
\hline Time $*$ Nema & 39 & 8.8 & 0.00 & 24 & 4.0 & 0.01 \\
\hline Time $*$ Vert $*$ Nema & 39 & 15.1 & 0.00 & 24 & 2.1 & 0.49 \\
\hline Error & 273 & 3.9 & & 168 & 2.1 & \\
\hline \multicolumn{7}{|l|}{ Transpiration rate } \\
\hline Time & 13 & 0.0 & 0.00 & 8 & 0.0 & 0.00 \\
\hline Time * Block & 39 & 0.0 & 0.15 & 24 & 0.0 & 0.00 \\
\hline Time * Vert & 13 & 0.0 & 0.00 & 8 & 0.0 & 0.00 \\
\hline Time $*$ Nema & 39 & 0.0 & 0.00 & 24 & 0.0 & 0.00 \\
\hline Time $*$ Vert $*$ Nema & 39 & 0.0 & 0.00 & 24 & 0.0 & 0.05 \\
\hline Error & 273 & 0.0 & & 168 & 0.0 & 0.43 \\
\hline
\end{tabular}

${ }^{a}$ Degrees of freedom based on split-plot analysis of variance.

b Type III mean square.

c $P$-value from $F$ test based on degrees of freedom.

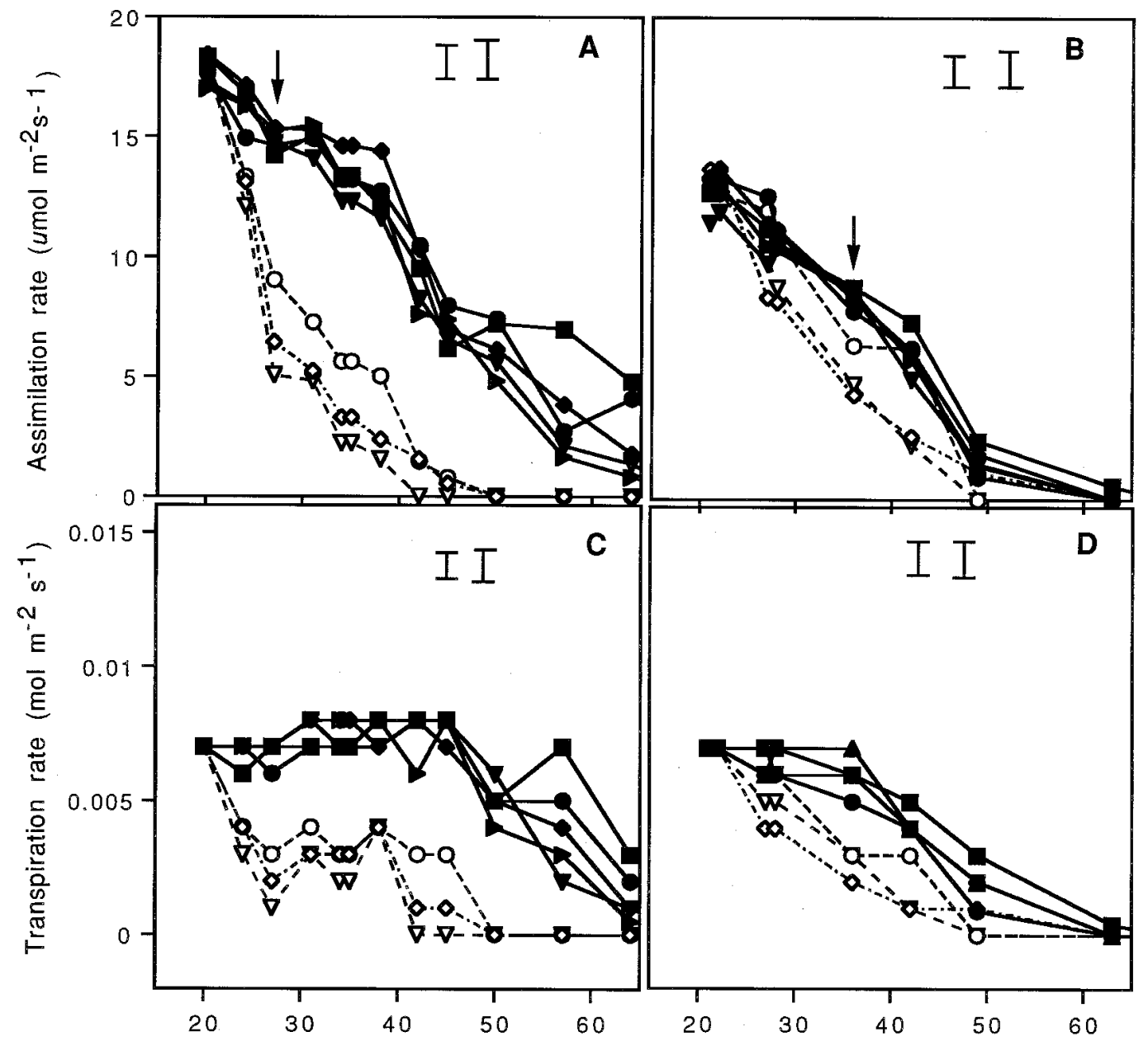

Days after planting

Fig. 1. Assimilation rate (A and $\mathbf{B})$ and transpiration rate $(\mathbf{C}$ and $\mathbf{D})$ of leaves in cohort 1 from the time of emergence (20 days after planting) until 64 days after planting. The dotted lines and open symbols represent plants inoculated with both Pratylenchus penetrans and Verticillium dahliae. The solid lines and closed symbols represent control plants (squares), plants inoculated with $P$. penetrans only (diamonds $=$ low inoculum level; circles $=$ medium inoculum level; inverted triangles $=$ high inoculum level), and plants inoculated with $V$. dahliae only (triangles). The arrows indicate the time when visible symptoms were first observed on leaves. The error bars represent least significant differences for comparisons of two treatments at the same time or at different times (right) and for comparisons of a single treatment at different times (left). 
As the plants grew, new leaves were assigned sequentially to cohorts 2 to 7 (in experiment 1) or 2 to 9 (in experiment 2) at approximately weekly intervals. Cohorts consisted of one leaf from each plant, for a total of four leaves per cohort per treatment. Data on the incidence and severity of disease were collected from leaf cohorts of different ages on every sampling date.

Gas exchange was analyzed as a "repeated measures" design with plants as the main experimental unit and time as the repeated measure within plants. Because of defoliation, the data sets were unbalanced, so abscised or necrotic leaves were assigned a value of zero for photosynthesis and transpiration. Analysis of variance was performed on the resulting balanced data set with SAS procedure GLM using the REPEATED statement. The GreenhouseGeisser correction for autocorrelation was applied to degrees of freedom for $F$ tests involving time (SAS Institute, Cary, NC); least square differences for comparing treatments at the same time or at different times were calculated according to Milleken and Johnson (18).

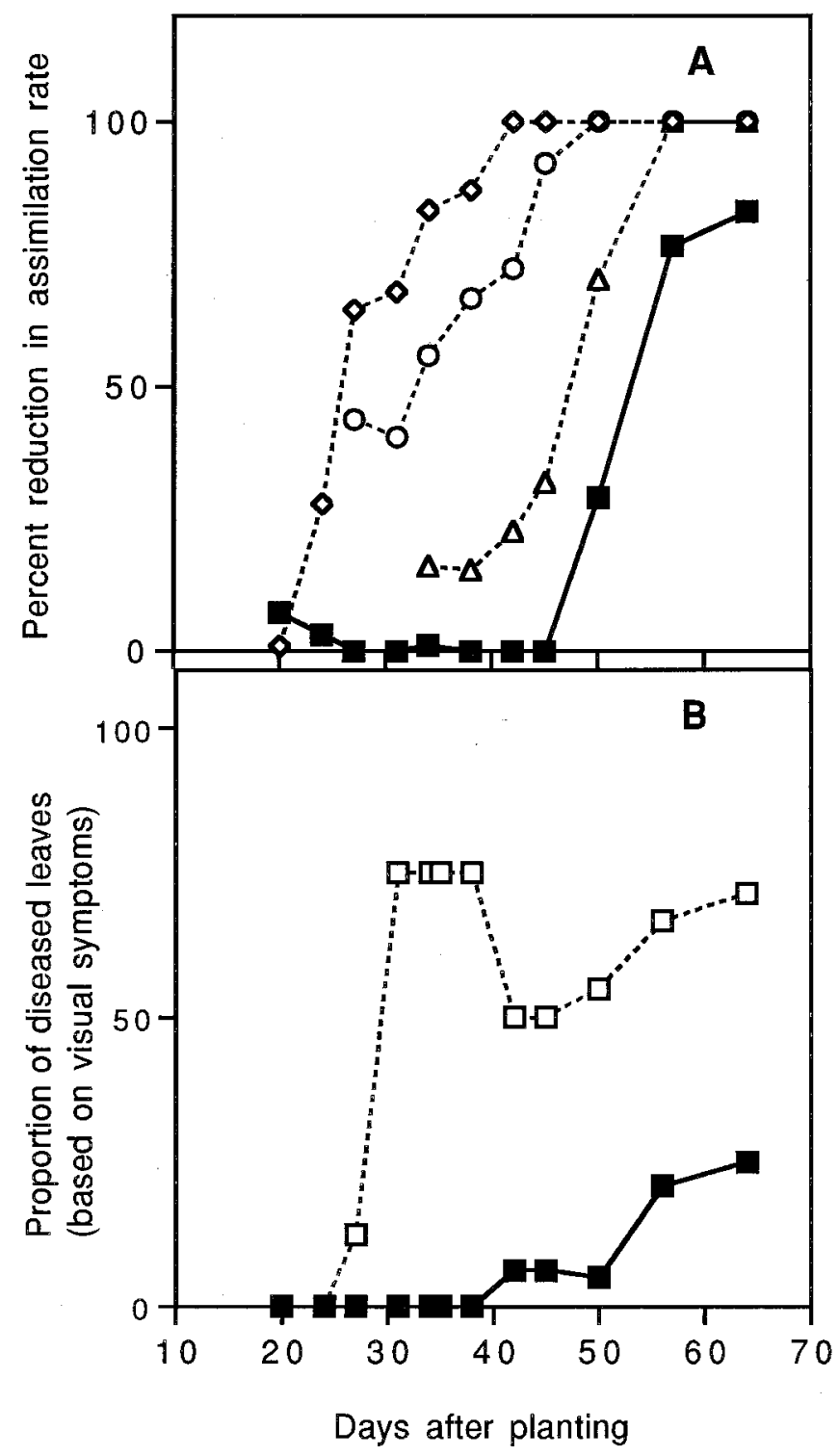

Fig. 2. A, Average assimilation rate in leaves of plants exposed to both Pratylenchus penetrans (2.5 nematodes per $\mathrm{cm}^{3}$ of soil) and Verticillium dahliae (dashed lines: diamonds $=$ cohort 1 ; circles $=$ cohort 2 ; triangles $=$ cohort 3 ) and plants treated with $V$. dahliae only (solid line: closed squares $=$ cohort 1 ), relative to the assimilation rate of control plants. B, Proportion of chlorotic or necrotic leaves in all leaf cohorts of plants exposed to P. penetrans ( 2.5 nematodes per $\mathrm{cm}^{3}$ of soil) and $V$. dahliae (open squares) and plants exposed to $V$. dahliae alone (closed squares).
The incidence of disease among leaves was estimated from light use efficiency, in mol of $\mathrm{CO}_{2}$ fixed per mol of photosynthetically active radiation (PAR), on the assumption that leaves able to fix $0.02 \mathrm{~mol}$ of $\mathrm{CO}_{2}$ per mole photon are healthy. Disease incidence was expressed as the number of leaves within each cohort, out of a total of four, which did not meet this photosynthetic criterion.

Disease severity was estimated from visual symptoms of chlorosis, necrosis, and wilting and from proportionate differences in carbon assimilation rate between treated and control plants. The average life span of each leaf cohort was calculated by averaging the number of days elapsed from the day when leaves were first tagged and measured until the day when their carbon assimilation rate was equal to zero.

Nematodes and $V$. dahliae were assayed from plants on the last sampling date, 80 and 70 days after planting in experiments 1 and 2 , respectively. Nematodes were recovered from $2 \mathrm{~g}$ of fresh root incubated on Baermann funnels for 2 days. Colony-forming units of $V$. dahliae were counted in plant sap incubated for 2 weeks on a semiselective medium.

\section{RESULTS}

There was a significant nematode-fungus interaction affecting photosynthesis of the oldest leaf cohort measured in one experiment and affecting transpiration in both experiments (Table 1). The lack of a significant effect on assimilation rate in experiment 2 was due to only weak effects from the moderate nematode dose in the combined nematode-fungus treatments. Assays showed that both $V$. dahliae and $P$. penetrans were present in plants, and the reason for the apparent lack of disease is not clear.

Compared to infection by either pathogen alone, joint infection by $V$. dahliae and $P$. penetrans reduced $(P=0.05)$ the assimilation rate of the first leaf cohort starting 4 days after tagging in experiment 1 (Fig. 1). Visual symptoms typical of reduced photosynthesis were first apparent 7 days after tagging. At this time, the light use efficiency of diseased leaves was less than $0.02 \mathrm{~mol}$ of $\mathrm{CO}_{2}$ fixed per mol of incident PAR, compared to 0.04 or more in control leaves. The assimilation rate in all treatments declined as the leaves aged, and significant differences between treatments disappeared when healthy leaves senesced about 50 days after tagging (approximately 70 days after inoculation). There was no significant $(P=0.05)$ difference at any time between the treatments with $P$. penetrans only or between the nematode- or fungus-only treatments and the noninfested control. Similar results were obtained from leaf cohorts $2-4$. The assimilation rate of leaf cohorts 5-7 remained fairly constant in the control and single-pathogen treatments from the time leaves appeared until the end of the experiment. The assimilation rate of leaves in the combination treatments declined.

Treatment effects on leaf transpiration rate were similar to those observed for photosynthesis (Fig. 1). There were reduced transpiration rates in the combination treatments, compared to treatments with either pathogen alone or the noninoculated control on most sampling dates. Reductions in transpiration rates in leaf cohort 1 were first observed 4 and 6 days after tagging in experiments 1 and 2 , respectively. The sensitivity of both photosynthesis and transpiration to concomitant infection was similar, since reductions in both parameters occurred at about the same time. However, concomitant infection caused a more drastic reduction in photosynthesis than in transpiration. At 35 days after planting, photosynthesis and transpiration in leaf cohort 1 , averaged among experiments, were 62 and $51 \%$ of the control rates, respectively.

Disease progress based on the percentage reduction in assimilation rate in cohorts 1-3 in the combination treatment with a high initial level of nematode inoculum and cohort 1 in the fungus-only treatment are shown in Figure 2. The initial reduction in assimilation rate was 1,44 , and $16 \%$ in cohorts $1-3$ and ranged from 0 to $18 \%$ in cohorts 4-7 (data not shown). Values for the slopes of 
regression lines calculated from the day of tagging until all leaves died were $4.3,2.7$, and 4.0 for cohorts $1-3$, respectively. The slope of the regression line for the fungus-only treatment calculated from 45 to 62 days after planting was 4.6. Slopes for the fungus-only treatment and for the combination treatments for cohorts 1 and 3 were not significantly different $(P=0.05)$. Leaf cohorts 2 and 3 in the fungus-only treatment were similar, but disease progress was delayed 8 to 10 days, compared to disease progress in cohort 1 in the same treatment (data not shown in Fig. 2). Disease progress, based on visual symptoms of all leaf cohorts (Fig. 2B), progressed rapidly between 25 to 30 days after planting. Because of the senescence of leaf cohort 1 and the high level of initial stress in leaf cohort 2, most leaves were visually symptomatic until the appearance of leaf cohort 4, 42 days after planting. In the fungus

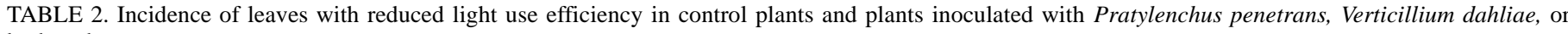
both pathogens ${ }^{\mathrm{a}}$

\begin{tabular}{|c|c|c|c|c|c|c|c|c|c|c|c|c|c|}
\hline \multirow[b]{2}{*}{ Treatment $^{\mathrm{b}}$} & \multirow[b]{2}{*}{ Cohort } & \multicolumn{12}{|c|}{ Days after planting (inoculation) } \\
\hline & & 20 & 24 & 27 & 31 & 35 & 42 & 45 & 50 & 57 & 64 & 71 & 78 \\
\hline \multirow[t]{7}{*}{ Control } & 7 & $\ldots$ & $\ldots$ & $\ldots$ & $\ldots$ & $\ldots$ & $\ldots$ & $\ldots$ & $\ldots$ & $\ldots$ & 0 & 0 & 0 \\
\hline & 6 & $\ldots$ & $\ldots$ & $\ldots$ & $\ldots$ & $\ldots$ & $\ldots$ & $\ldots$ & 0 & 0 & 0 & 0 & 0 \\
\hline & 5 & $\ldots$ & $\ldots$ & $\ldots$ & $\ldots$ & $\ldots$ & $\ldots$ & 0 & 0 & 0 & 0 & 0 & 0 \\
\hline & 4 & $\ldots$ & $\ldots$ & $\ldots$ & $\ldots$ & $\ldots$ & 0 & 0 & 0 & 0 & 0 & 0 & 0 \\
\hline & 3 & $\ldots$ & $\ldots$ & $\ldots$ & $\ldots$ & 0 & 0 & 0 & 0 & 0 & 1 & 1 & 2 \\
\hline & 2 & $\ldots$ & $\ldots$ & 0 & 0 & 0 & 0 & 0 & 0 & 0 & 1 & 3 & 3 \\
\hline & 1 & 0 & 0 & 0 & 0 & 0 & 0 & 0 & 1 & 0 & 1 & 3 & 4 \\
\hline \multirow[t]{7}{*}{ V. dahliae } & 7 & $\ldots$ & $\ldots$ & $\ldots$ & $\ldots$ & $\ldots$ & $\ldots$ & $\ldots$ & $\ldots$ & $\ldots$ & 0 & 0 & 0 \\
\hline & 6 & $\ldots$ & $\ldots$ & $\ldots$ & $\ldots$ & $\ldots$ & $\ldots$ & $\ldots$ & $\ldots$ & 0 & 0 & 0 & 0 \\
\hline & 5 & $\ldots$ & $\ldots$ & $\ldots$ & $\ldots$ & $\ldots$ & $\ldots$ & $\ldots$ & 0 & 0 & 0 & 0 & 1 \\
\hline & 4 & $\ldots$ & $\ldots$ & $\ldots$ & $\ldots$ & $\ldots$ & 0 & 0 & 0 & 1 & 0 & 2 & 1 \\
\hline & 3 & $\ldots$ & $\ldots$ & $\ldots$ & $\ldots$ & 0 & 0 & 0 & 0 & 1 & 1 & 0 & 2 \\
\hline & 2 & $\ldots$ & $\ldots$ & 0 & 0 & 0 & 0 & 0 & 0 & 0 & 3 & 3 & 4 \\
\hline & 1 & 0 & 0 & 0 & 0 & 0 & 0 & 0 & 1 & 3 & 3 & 4 & 4 \\
\hline \multirow{7}{*}{$\begin{array}{l}V . \text { dahliae }+P \text {. penetrans } \\
(\text { low })\end{array}$} & 7 & $\ldots$ & $\ldots$ & $\ldots$ & $\ldots$ & $\ldots$ & $\ldots$ & $\ldots$ & $\ldots$ & $\ldots$ & 0 & 0 & 2 \\
\hline & 6 & $\ldots$ & $\ldots$ & $\ldots$ & $\ldots$ & $\ldots$ & $\ldots$ & $\ldots$ & $\ldots$ & 0 & 0 & 2 & 4 \\
\hline & 5 & $\ldots$ & $\ldots$ & $\ldots$ & $\ldots$ & $\ldots$ & $\ldots$ & $\ldots$ & 0 & 0 & 1 & 4 & 4 \\
\hline & 4 & $\ldots$ & $\ldots$ & $\ldots$ & $\ldots$ & $\ldots$ & 0 & 0 & 0 & 0 & 4 & 4 & 4 \\
\hline & 3 & $\ldots$ & $\ldots$ & $\ldots$ & $\ldots$ & 0 & 0 & 1 & 2 & 4 & 4 & 4 & 4 \\
\hline & 2 & $\ldots$ & $\ldots$ & 1 & 0 & 3 & 3 & 4 & 4 & 4 & 4 & 4 & 4 \\
\hline & 1 & 0 & 0 & 3 & 3 & 3 & 3 & 4 & 4 & 4 & 4 & 4 & 4 \\
\hline \multirow{7}{*}{$\begin{array}{l}V . \text { dahliae }+P . \text { penetrans } \\
\text { (medium) }\end{array}$} & 7 & $\ldots$ & $\ldots$ & $\ldots$ & $\ldots$ & $\ldots$ & $\ldots$ & $\ldots$ & $\ldots$ & $\ldots$ & 0 & 0 & 0 \\
\hline & 6 & $\ldots$ & $\ldots$ & $\ldots$ & $\ldots$ & $\ldots$ & $\ldots$ & $\ldots$ & $\ldots$ & 0 & 0 & 1 & 4 \\
\hline & 5 & $\ldots$ & $\ldots$ & $\ldots$ & $\ldots$ & $\ldots$ & $\ldots$ & $\ldots$ & 0 & 0 & 2 & 3 & 4 \\
\hline & 4 & $\ldots$ & $\ldots$ & $\ldots$ & $\ldots$ & $\ldots$ & 0 & 0 & 0 & 0 & 3 & 4 & 4 \\
\hline & 3 & $\ldots$ & $\ldots$ & $\ldots$ & $\ldots$ & 0 & 1 & 0 & 2 & 3 & 4 & 4 & 4 \\
\hline & 2 & $\ldots$ & $\ldots$ & 0 & 0 & 0 & 3 & 4 & 4 & 4 & 4 & 4 & 4 \\
\hline & 1 & 0 & 0 & 1 & 2 & 2 & 3 & 4 & 4 & 4 & 4 & 4 & 4 \\
\hline \multirow{7}{*}{$\begin{array}{l}V . \text { dahliae }+P . \text { penetrans } \\
\text { (high) }\end{array}$} & 7 & $\ldots$ & $\ldots$ & $\ldots$ & $\ldots$ & $\ldots$ & $\ldots$ & $\ldots$ & $\ldots$ & $\ldots$ & 0 & 1 & 4 \\
\hline & 6 & $\ldots$ & $\ldots$ & $\ldots$ & $\ldots$ & $\ldots$ & $\ldots$ & $\ldots$ & $\ldots$ & 0 & 0 & 2 & 4 \\
\hline & 5 & $\ldots$ & $\ldots$ & $\ldots$ & $\ldots$ & $\ldots$ & $\ldots$ & $\ldots$ & 0 & 0 & 3 & 4 & 4 \\
\hline & 4 & $\ldots$ & $\ldots$ & $\ldots$ & $\ldots$ & $\ldots$ & 0 & 0 & 0 & 1 & 4 & 4 & 4 \\
\hline & 3 & $\ldots$ & $\ldots$ & $\ldots$ & $\ldots$ & 0 & 0 & 1 & 3 & 4 & 4 & 4 & 4 \\
\hline & 2 & $\ldots$ & $\ldots$ & 2 & 1 & 2 & 3 & 4 & 4 & 4 & 4 & 4 & 4 \\
\hline & 1 & 0 & 0 & 4 & 4 & 4 & 4 & 4 & 4 & 4 & 4 & 4 & 4 \\
\hline \multirow[t]{7}{*}{ P. penetrans (low) } & 7 & $\ldots$ & $\ldots$ & $\ldots$ & $\ldots$ & $\ldots$ & $\ldots$ & $\ldots$ & $\ldots$ & $\ldots$ & 0 & 0 & 0 \\
\hline & 6 & $\ldots$ & $\ldots$ & $\ldots$ & $\ldots$ & $\ldots$ & $\ldots$ & $\ldots$ & $\ldots$ & 0 & 0 & 0 & 0 \\
\hline & 5 & $\ldots$ & $\ldots$ & $\ldots$ & $\ldots$ & $\ldots$ & $\ldots$ & $\ldots$ & 0 & 0 & 1 & 0 & 0 \\
\hline & 4 & $\ldots$ & $\ldots$ & $\ldots$ & $\ldots$ & $\ldots$ & 0 & 0 & 0 & 0 & 0 & 1 & 1 \\
\hline & 3 & $\ldots$ & $\ldots$ & $\ldots$ & $\ldots$ & 0 & 0 & 0 & 0 & 0 & 0 & 2 & 2 \\
\hline & 2 & $\ldots$ & $\ldots$ & 0 & 0 & 0 & 0 & 0 & 0 & 1 & 2 & 3 & 3 \\
\hline & 1 & 0 & 0 & 0 & 0 & 0 & 0 & 0 & 1 & 2 & 2 & 4 & 4 \\
\hline \multirow[t]{7}{*}{ P. penetrans (medium) } & 7 & $\cdots$ & $\cdots$ & $\ldots$ & $\ldots$ & $\ldots$ & $\ldots$ & $\ldots$ & $\ldots$ & $\ldots$ & 0 & 0 & 0 \\
\hline & 6 & $\ldots$ & $\ldots$ & $\ldots$ & $\ldots$ & $\ldots$ & $\ldots$ & $\ldots$ & $\ldots$ & 0 & 0 & 0 & 0 \\
\hline & 5 & $\ldots$ & $\ldots$ & $\ldots$ & $\ldots$ & $\ldots$ & $\ldots$ & $\ldots$ & 0 & 0 & 0 & 0 & 0 \\
\hline & 4 & $\ldots$ & $\ldots$ & $\ldots$ & $\ldots$ & $\ldots$ & 0 & 0 & 0 & 0 & 0 & 0 & 0 \\
\hline & 3 & $\ldots$ & $\ldots$ & $\ldots$ & $\ldots$ & 0 & 0 & 0 & 0 & 0 & 0 & 0 & 0 \\
\hline & 2 & $\ldots$ & $\ldots$ & 0 & 0 & 0 & 0 & 0 & 0 & 0 & 0 & 1 & 1 \\
\hline & 1 & 0 & 0 & 0 & 0 & 0 & 0 & 0 & 0 & 1 & 1 & 2 & 1 \\
\hline \multirow[t]{7}{*}{ P. penetrans (high) } & 7 & $\ldots$ & $\ldots$ & $\ldots$ & $\ldots$ & $\ldots$ & $\ldots$ & $\ldots$ & $\ldots$ & $\ldots$ & 0 & 0 & 0 \\
\hline & 6 & $\ldots$ & $\ldots$ & $\ldots$ & $\ldots$ & $\ldots$ & $\ldots$ & $\ldots$ & $\ldots$ & 0 & 0 & 0 & 0 \\
\hline & 5 & $\ldots$ & $\ldots$ & $\ldots$ & $\ldots$ & $\ldots$ & $\ldots$ & $\ldots$ & 0 & 0 & 0 & 0 & 0 \\
\hline & 4 & $\ldots$ & $\ldots$ & $\ldots$ & $\ldots$ & $\ldots$ & 0 & 0 & 0 & 0 & 0 & 0 & 0 \\
\hline & 3 & $\ldots$ & $\ldots$ & $\ldots$ & $\ldots$ & 0 & 0 & 0 & 0 & 0 & 1 & 1 & 3 \\
\hline & 2 & $\ldots$ & $\ldots$ & 0 & 0 & 0 & 0 & 0 & 1 & 0 & 2 & 4 & 4 \\
\hline & 1 & 0 & 0 & 0 & 0 & 0 & 0 & 1 & 0 & 3 & 2 & 4 & 4 \\
\hline
\end{tabular}

${ }^{a}$ Light use efficiency of $0.20 \mathrm{~mol}$ of $\mathrm{CO}_{2}$ fixed, or less, per mol of photosynthetically active radiation used.

${ }^{\text {b }}$ In treatments with $P$. penetrans, three different initial levels of inoculum were used (low, medium, and high). 
treatment, visual symptoms began later and progressed gradually.

Table 2 shows the incidence of leaves with a light use efficiency less than $0.02 \mathrm{~mol}$ of $\mathrm{CO}_{2}$ fixed per mol of PAR. Naturally senescing leaves also have reduced photosynthetic capacity but typically do not approach this level until they are 50 days old or more, as can be seen in data collected from control plants. The incidence of leaves with reduced photosynthetic capacity in the nematode-only treatments was similar to that of control plants (data not shown). Few plants infected by only the fungus had diseased leaves in any leaf cohort except cohort 1 until 64 days after inoculation. Some diseased leaves were positioned acropetally to healthy leaves in the fungus-only treatment. Disease incidence in the combination treatment with a high initial level of nematode inoculum reached $100 \%$ in $7,18,22$, and 22 days after leaves were tagged, in cohorts 1-4, respectively. Except for cohort 2, no leaves were classified as diseased at the time of tagging. Increasing the nematode dose had no impact on disease incidence in plants inoculated with $V$. dahliae.

Concomitant infection significantly $(P=0.01)$ reduced the number of days that each leaf cohort contributed to photosynthesis for the potato plants (Table 3). Leaves in cohorts 1 and 2 died about 3 weeks earlier in the combination treatments. Concomitant infection reduced the leaf life span of cohorts 3 and 4 at least 2 weeks by the end of the experiment. Because the control leaves in these cohorts were still alive when the experiment ended, it was not possible to calculate the actual reduction in the life span of these and younger leaf cohorts.

Pathogen assays at the end of the experiments determined that all plants were infected by the organisms with which they had been inoculated. There were no statistical differences in the number of colony-forming units of $V$. dahliae in $0.10 \mathrm{ml}$ of sap from plants in the single-pathogen and combination treatments. There were more $(P=0.01)$ nematodes recovered from the combination treatments than from the nematode-only treatment in experiment 1 , but the reverse occurred for experiment 2 . In experiment 1 , the final nematode density did not vary according to the initial inoculum dose. In experiment 2 , the final nematode density was linearly related to the initial dose $(P=0.01)$ when $V$. dahliae was present, but the relationship was quadratic when the fungus was absent.

\section{DISCUSSION}

Concomitant infection by $V$. dahliae and $P$. penetrans altered the time course of physiological and visual symptoms typical of

TABLE 3. Number of days during which leaves assimilated carbon dioxide, from the day when they were first tagged until the day when they died or the experiment ended

\begin{tabular}{|c|c|c|c|c|c|c|c|}
\hline \multirow[b]{2}{*}{ Treatment $^{\mathrm{a}}$} & \multicolumn{7}{|c|}{ Leaf cohort $^{\mathrm{b}}$} \\
\hline & 1 & 2 & 3 & 4 & 5 & 6 & 7 \\
\hline Control & 49 & 44 & 40 & 36 & 28 & 21 & 14 \\
\hline P. penetrans (low) & 44 & 41 & 40 & 36 & 28 & 21 & 14 \\
\hline P. penetrans (medium) & 51 & 49 & 43 & 36 & 28 & 21 & 14 \\
\hline P. penetrans (high) & 44 & 41 & 40 & 36 & 28 & 21 & 14 \\
\hline V. dahliae & 44 & 41 & 41 & 36 & 28 & 21 & 14 \\
\hline P. penetrans (low) & & & & & & & \\
\hline$+V$. dahliae & 23 & 20 & 22 & 20 & 21 & 20 & 14 \\
\hline P. penetrans (medium) & & & & & & & \\
\hline$+V$. dahliae & 25 & 23 & 17 & 26 & 23 & 19 & 14 \\
\hline P. penetrans (high) & & & & & & & \\
\hline$+V$. dahliae & 22 & 18 & 19 & 20 & 18 & 21 & 14 \\
\hline $\mathrm{LSD}_{0.01}$ & 9 & 7 & 7 & 3 & 2 & $\mathrm{NS}^{\mathrm{c}}$ & NS \\
\hline
\end{tabular}

a In treatments with $P$. penetrans, three different initial levels of inoculum were used (low, medium, and high).

${ }^{b}$ Leaf cohorts 1 through 7 were tagged 20, 27, 35, 42, 50, 57, and 64 days after transplanting, respectively. The experiment ended 78 days after transplanting.

c No significant difference. infection by $V$. dahliae. Plants growing in soil infested with only the fungus were infected but remained in the latent phase of disease development, as can occur with low inoculum doses of $V$. dahliae (16). In the presence of the nematode, leaf senescence was accelerated, and leaf life span decreased. Nematode infection alone, even at initial inoculum doses representative of commercial field conditions, did not produce these symptoms. So in terms of visual symptoms, the interactive effects of the nematode and fungus appeared very similar to that which would be expected from increasing the initial inoculum level of $V$. dahliae.

However, the progression of disease within plants concomitantly infected with $V$. dahliae and $P$. penetrans differed from that of plants infected with $V$. dahliae alone on the basis of physiological measurements. Bowden and Rouse (3) observed a local phase of disease, in which healthy and unhealthy leaves were interspersed along the main stem axis. They attributed this phenomenon to the nonuniform infection and subsequent colonization of xylem vessels. We did not observe a local phase in the nematode plus fungus treatments. The progressive impairment of leaves on concomitantly infected plants in our experiment was fairly invariant to leaf position. In the course of our experiments, there was no instance of healthy leaves appearing between diseased leaves. Rather, we saw from an early point progressively more severe disease on older cohorts, consistent with the systemic phase described by Bowden and Rouse. Based on their data, this stage of the fungal wilt disease is most likely due to the extensive plugging of xylem vessels at the base of the plant once the fungus has breached the plant's responses to contain mycelial growth. Bowden and Rouse observed a transition from the local to the systemic phase of disease at initial inoculum levels greater than 100 propagules of $V$. dahliae per $g$ of soil, which was well in excess of our initial inoculum. Even though leaves on our concomitantly infected plants were sequentially rather than randomly symptomatic, the rate at which leaves became diseased did not progressively increase with each new leaf cohort, since the slopes of cohort 1 did not differ from that of cohort 3 .

A critical resistance to water flow sufficient to reduce photosynthesis and transpiration occurred early in our experiments, at levels of the fungus and the nematode capable of producing this effect only when both pathogens are present together. That resistance could have been due to extensive dysfunction of the root system or the plugging of xylem vessels in the potato stem or both. Nematodes affected the root conductivity of Katahdin potato (13), but if $P$. penetrans played this role in our experiments it seems likely that, given the sensitivity of our measurements and the range of nematode densities used, some response to nematode infection alone would have been detected. Our data support the conclusion of Kotcon and Loria (13) that P. penetrans has no impact on transpiration and root conductivity of Russet Burbank potato, and the data do not refute the commonly held assumption that, for this cultivar, the fungus is the primary pathogen in the $V$. dahliae- $P$. penetrans interaction.

Beckman's model (1) describes the movement of vascular wilt fungi as both a passive process through the transpiration stream and an active process of longitudinal and lateral spread through xylem vessels by mycelial growth. The role of $P$. penetrans in our experiments could have been to increase, early on, the number of infection events by the fungus, as demonstrated by Bowers et al. (5) for Superior potato. If so, one might expect that the aggregated pattern of root infection typical of nematodes would produce an accentuated local phase of symptom expression, which we did not observe.

An alternative explanation is that the nematode enhanced host susceptibility to mycelial growth of the fungus. Increased susceptibility of the plant might allow $V$. dahliae to move quickly in both the lateral and the longitudinal direction through the vascular system. In this scenario, the nematode would not necessarily enhance the ability of $V$. dahliae to gain access to the xylem, but rather 
would enhance its ability to colonize the plant once entry is gained. The early appearance of the nematode effect in our experiments, the lack of a dose-response relationship for $P$. penetrans in the interaction, and data from field experiments showing a qualitative role of $P$. penetrans affecting yield loss in $V$. dahliae-infested soil (26) suggests that the role of the nematode as an inducer of plant susceptibility to colonization by $V$. dahliae merits study.

Based on the body of experimental work on $V$. dahliae, several models have been proposed to describe disease progression (11, 12,25). A temporal relationship between the incidence of $V$. dahliae in potato stems and accelerated leaf aging was used by Johnson (12) to model disease progress and yield loss. Termorshuizen and Rouse (25) also coupled a Verticillium model to a potato crop growth model, accounting for infection and colonization processes by the fungus explicitly. Gutierrez et al. (11) related the soil inoculum density of $V$. dahliae to the progression of foliar symptoms in cotton. Each of these models explains yield loss on the basis of disease dynamics through the effect on $\mathrm{CO}_{2}$ assimilation and light interception on crop growth. For these types of models to work when nematodes are also present, a further assumption is required - that nematodes increase the efficiency of the fungus inoculum with no independent effects on symptom expression. Our experiments demonstrate that even in the presence of the nematode, leaves of potato plants infected with $V$. dahliae die in an acropetal progression. To satisfactorily reflect the impact of $P$. penetrans in combination with $V$. dahliae, models should accelerate leaf senescence and incorporate the accompanying consequences of a reduced ability to use as well as to intercept radiation.

There are several advantages in using physiological rather than visual symptoms for studies on the potato early dying disease. The impact of the nematode-fungus interaction is detected earlier in physiological than in visual symptoms, and measurement of physiological symptoms facilitates the duplication of experiments. For example, Faulkner et al. (8) concluded that $P$. minyus enhanced susceptibility of peppermint to Verticillium wilt on the basis of the timing and severity of visual symptom expression in plants infected by nematodes and fungi spatially separated by a doubleroot technique. Conroy et al. (6) failed to confirm their results using $P$. penetrans and $V$. dahliae in a split-root tomato system. These researchers based their conclusions on the incidence of diseased plants because of the highly subjective nature of disease severity assessments. The use of physiological measurements greatly reduces subjectivity and should prove useful for studying the mechanisms responsible for nematode-fungus interactions.

\section{ACKNOWLEDGMENTS}

This research was supported by USDA-ARS competitive grant \#581275-1-136 and USDA-NRI competitive grant \#92-37302-7609. We thank T. Sharkey for his advice, M. Clayton for statistical consulting, and $\mathrm{S}$. Vicen for technical assistance.

\section{LITERATURE CITED}

1. Beckman, C. H. 1987. The Nature of Wilt Diseases of Plants. American Phytopathological Society, St. Paul, MN.

2. Bowden, R. L., and Rouse, D. I. 1991. Effects of Verticillium dahliae on gas exchange of potato. Phytopathology 81:293-301.

3. Bowden, R. L., and Rouse, D. I. 1991. Chronology of gas exchange effects and growth effects of infection by Verticillium dahliae in potato. Phytopathology 81:301-310.
4. Bowden, R. L., Rouse, D. I., and Sharkey, T. D. 1990. Mechanisms of photosynthetic decrease by Verticillium dahliae in potato. Plant Physiol. 94:1048-1055.

5. Bowers, J. H., Nameth, S. T., Riedel, R. M., and Rowe, R. C. 1996 Infection and colonization of potato roots by Verticillium dahliae as affected by Pratylenchus penetrans and P. crenatus. Phytopathology 86: 614-621.

6. Conroy, J. J., Green, R. J., Jr., and Ferris, J. M. 1972. Interaction of Verticillium albo-atrum and the root-lesion nematode, Pratylenchus penetrans, in tomato roots at controlled inoculum densities. Phytopathology 62:362-366

7. Davis, J. R., Pavek, J. J., and Corsini, D. L. 1983. A sensitive method for quantifying Verticillium dahliae colonization in plant tissue and evaluating resistance among potato genotypes. Phytopathology 73:10091014.

8. Faulkner, L. R., Bolander, W. J., and Skotland, C. B. 1970. Interaction of Verticillium dahliae and Pratylenchus minyus in Verticillium wilt of peppermint: Influence of the nematode as determined by a double root technique. Phytopathology 60:100-103.

9. Francl, L. J., Rowe, R. C., Riedel, R. M., and Madden, L. V. 1988. Effects of three soil types on potato early dying disease and associated yield reduction. Phytopathology 78:159-166.

10. Gaudreault, S. M., Powelson, M. L., Christensen, N. W., and Crowe, F. J. 1995. Soil water pressure and Verticillium dahliae interactions on potato. Phytopathology 85:1542-1546.

11. Gutierrez, A. P., DeVay, J. E., Pullman, G. S., and Friebertshauser, G. E. 1983. A model of Verticillium wilt in relation to cotton growth and development. Phytopathology 73:89-95.

12. Johnson, K. B. 1988. Modeling the influences of plant infection rate and temperature on potato foliage and yield losses caused by Verticillium dahliae. Phytopathology 78:1198-1205.

13. Kotcon, J. B., and Loria, R. 1986. Influence of Pratylenchus penetrans on plant growth and water relations of potato. J. Nematol. 18:385-392.

14. Kotcon, J. B., Rouse, D. I., and Mitchell, J. E. 1985. Interactions of Verticillium dahliae, Colletotrichum coccodes, Rhizoctonia solani, and Pratylenchus penetrans in the early dying syndrome of Russet Burbank potatoes. Phytopathology 75:68-74.

15. MacGuidwin, A. E., and Rouse, D. I. 1990. Role of Pratylenchus penetrans in the potato early dying disease of Russet Burbank potato. Phytopathology 80:1077-1082.

16. Malek, C. J. 1994. Influence of Pratylenchus penetrans on colonization of potato by Verticillium dahliae. M.S. thesis, University of Wisconsin, Madison.

17. Martin, M. J., Riedel, R. M., and Rowe, R. C. 1982. Verticillium dahliae and Pratylenchus penetrans: Interactions in early dying complex of potato in Ohio. Phytopathology 72:640-644.

18. Milleken, G. A., and Johnson, D. E. 1984. Analysis of Messy Data. Vol. 1, Designed Experiments. Van Nostrand Reinhold, New York.

19. Nicot, P. C., and Rouse, D. I. 1987. Relationship between soil inoculum density of Verticillium dahliae and systemic colonization of potato stems in commercial fields over time. Phytopathology 77:1346-1355.

20. Olthof, Th. H. A. 1983. Reaction of six potato cultivars to Pratylenchus penetrans. Can. J. Plant Pathol. 5:285-288.

21. Powelson, M. L. 1979. Verticillium wilt of potatoes in irrigated sands: The Oregon experience. Ore. Agric. Exp. Stn. Tech. Pub. 5106.

22. Riedel, R. M., and Rowe, R. C. 1985. Lesion nematode involvement in potato early dying disease. Am. Potato J. 62:163-171.

23. Rowe, R. C. Riedel, R. M., and Martin, M. J. 1985. Synergistic interactions between Verticillium dahliae and Pratylenchus penetrans in potato early dying disease. Phytopathology 75:412-418.

24. Saeed, I. A. M., MacGuidwin, A. E., and Rouse, D. I. 1997. Synergism of Pratylenchus penetrans and Verticillium dahliae manifested by reduced gas exchange in potato. Phytopathology 87:435-439.

25. Termorshuizen, A. J., and Rouse, D. I. 1993. Toward a mechanistic model for the Verticillium dahliae-potato system. Neth. J. Plant Pathol. 99 Suppl. 3: 201-218.

26. Wheeler, T. A., Madden, L. V., Rowe, R. C., and Riedel, R. M. Modeling of yield loss in potato early dying caused by Pratylenchus penetrans and Verticillium dahliae. J. Nematol. 24:99-102. 